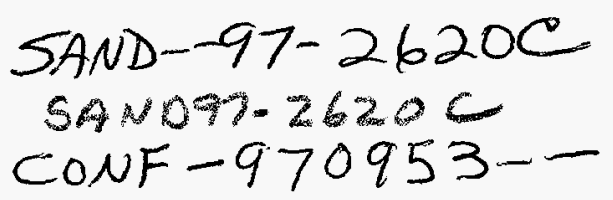

\title{
SIMULTANEOUS P AND B DIFFUSION, IN-SITU SURFACE PASSIVATION, IMPURITY FILTERING AND GETTERING FOR HIGH-EFFICIENCY SILICON SOLAR CELLS
}

\author{
Thomas Krygowski, Ajeet Rohatgi \\ Georgia Institute of Technology, Atlanta Georgia 30332 \\ Douglas Ruby
}

Sandia National Laboratories, Albuquerque New Mexico 87123

\section{ABSTRACT}

A technique is presented to simultaneously diffuse boron and phosphorus in silicon, and grow an insitu passivating oxide in a single furnace step. It is shown that limited solid doping sources made from $P$ and B Spin-On Dopant (SOD) films can produce optimal $\mathrm{n}^{+}$ and $\mathrm{p}^{+}$profiles simultaneously without the deleterious effects of cross doping. A high quality passivating oxide is grown in-situ beneath the thin $(-60 \mathrm{~A})$ diffusion glass, resulting in low $J_{0}$ values below $100 \mathrm{fA} \mathrm{cm}^{2}$ for transparent $(\sim 100 \Omega / \square)$ phosphorus and boron diffusions. For the first time it is shown that impurities present in the boron SOD film can be effectively filtered out by employing separate source wafers, resulting in bulk lifetimes in excess of $1 \mathrm{~ms}$ for the sample wafers. The degree of lifetime degradation in the sources is related to the gettering efficiency of boron in silicon. This novel simultaneous diffusion, in-situ oxidation, impurity filtering and gettering technique was successfully used to produce $20.3 \% \mathrm{Fz}$, and $19.1 \% \mathrm{Cz}$ solar cells, in one furnace step.

\section{INTRODUCTION}

High temperature thermal processing can limit the throughput of a cell manufacturing line and potentially reduce cell efficiency through bulk lifetime degradation. To fabricate high efficiency solar cells with minimal thermal processing, simultaneous diffusion techniques can be employed to co-diffuse the emitter and Back Surface Field (BSF). Researchers at Sandia National Laboratories [1] have demonstrated an aluminum and phosphorus diffusion technique in which one high temperature $\left(>800^{\circ} \mathrm{C}\right.$ ) $\mathrm{POCl}_{3}$ diffusion step is used to codiffuse the emitter and pre-alloyed BSF, and grow a thick thermal oxide beneath the remaining phosphosilicate glass. Workers at IMEC have simultaneously diffused boron and phosphorus in an RTP using CVD doped oxides on opposite sides of a silicon wafer [2]. Using boron and phosphorus Spin-On Dopant (SOD) films in a conventional diffusion furnace, workers at UNSW have simultaneously formed the front and back groove diffusions for the double sided buried contact structure [3], reducing the number of thermal cycles from three to two. All of the above techniques result in a thick layer of diffusion glass on the wafer surfaces. This thick diffusion glass leads to a high reflectance when incorporated into a module and is therefore usually removed, thus

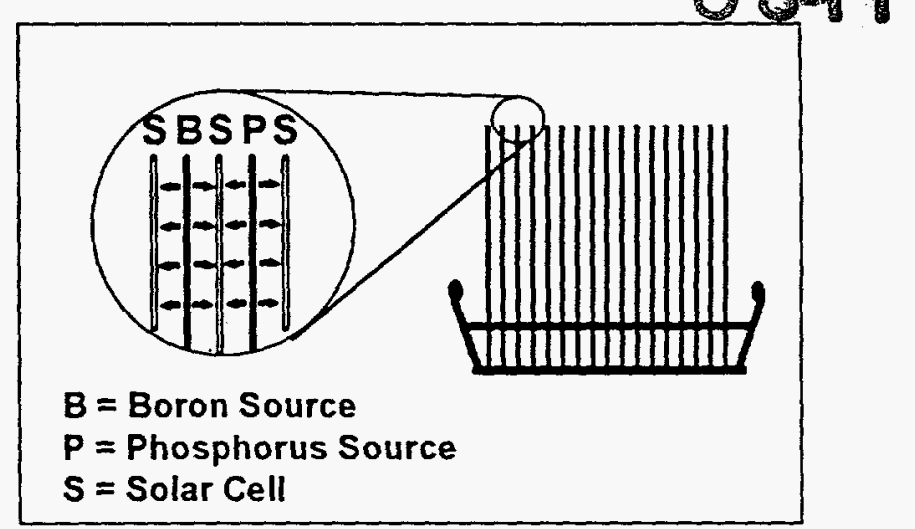

Figure 1. Wafer stacking arrangement for simultaneous $P$ and $P$ diffusion technique. The front sides of the Solar cells (S) face the Phosphorus (P) source wafers and the back sides face the Boron $(B)$ source wafers.

eliminating any possibility for in-situ surface passivation. In addition, $\mathrm{POCl}_{3}$ as well as the gasses typically used in CVD processes such as $\mathrm{SiH}_{4}, \mathrm{~B}_{2} \mathrm{H}_{6}$ and $\mathrm{PH}_{3}$ are highly toxic, and require significant expertise in handling and disposal. Our approach toward simultaneous diffusion, named the Dopant Oxide Solid Source (DOSS) technique [4], employs separate boron and phosphorus doping sources, which are interleaved with the solar cell wafers to simultaneously form a phosphorus emitter and boron BSF in a single furnace cycle. In the DOSS technique, the back sides of the solar cells $(S)$ face the boron sources (B), and the front sides face the phosphorus sources $(P)$ in a stacking arrangement shown in Figure 1. The $B$ and $P$ sources are fabricated in house from silicon wafers on which a controlled amount of the dopant oxide $\left(\mathrm{P}_{2} \mathrm{O}_{5}\right.$ and $\left.\mathrm{B}_{2} \mathrm{O}_{3}\right)$ is deposited. The DOSS technique, which was first presented at the $25^{\text {th }}$ Photovoltaics Specialists Conference [5], allows one to independently control the emitter and BSF doping profiles for a fixed thermal budget, by tailoring the concentration of $\mathrm{P}_{2} \mathrm{O}_{5}$ and $\mathrm{B}_{2} \mathrm{O}_{3}$ on the source wafers. In our earlier work [4] sources were made by depositing $\mathrm{P}_{2} \mathrm{O}_{5}$ or $\mathrm{B}_{2} \mathrm{O}_{3}$ on the source wafers using the liquid dopants $\mathrm{POCl}_{3}$ and $\mathrm{BBr}_{3}$ respectively in a pre-deposition step. In contrast to conventional solid, liquid, CVD or spin-on doping techniques, the residual phosphorous glass on the solar cell wafers was extremely thin $(\sim 60 \AA)$. This allowed for a thin thermal passivating oxide to be grown in-situ, while maintaining a total oxide thickness below about $150 \AA$, which will not significantly increase the reflectance of an 


\section{DISCLAMIER}

Portions of this document may be illegible in electronic image products. Images are produced from the best available original document. 


\section{DISCLAIMER}

This report was prepared as an account of work sponsored by an agency of the United States Government. Neithet the United States Government nor any agency thereof, nor any of their employees, makes any wartanty, express or implied, or assumes any legal liability or responsibility for the accuracy, completeness, or usefulness of any information, apparatus, product, or process disclosed, or represents that its use would not infringe privately owned rights. Reference herein to any specific commercial product, process, or service by trade name, trademark, manufacturer, or otherwise does not necessarily constitute or imply its endorsement, recommendation, or favoring by the United States Government or any agency thereof. The views and opinions of authors expressed herein do not necessarily state or reflect those of the United States Government or any agency thereof. 
AR-coated cell when incorporated into a module. This insitu oxide was shown [5] to provide excellent surface passivation for light phosphorus diffusions $(-90 \Omega / \square)$. resulting in virtually the same saturation current densities (Jo's) for in-situ as well as re-grown thermal oxide passivation.

The goal of this paper is to present recent advances in the DOSS simultaneous diffusion technique in which the solid doping sources are fabricated using phosphorus and boron Spin-On Dopant (SOD) films in place of $\mathrm{POCl}_{3}$ and $\mathrm{BBr}_{3}$. It will be shown that in addition to forming optimal emitter and BSF profiles simultaneously, and providing in-situ oxide surface passivation, one can obtain high minority carrier lifetimes from a relatively impure boron SOD film through a powerful contamination filtering action. Several efficiency-enhancement features are combined in the DOSS technique to produce $19-20 \%$ efficient solar cells in one thermal cycle, using commercially available spinon dopant films and a conventional diffusion furnace.

\section{EXPERIMENTAL}

Boron and phosphorus solid diffusion sources were made prior to each diffusion cycle by applying the same SOD film ( $B$ or $P$ ) to each side of a silicon source wafer. The source wafers are depleted after each diffusion cycle, and recycled (as sources) by a brief dip in $10 \%$ dilute $\mathrm{HF}$ to remove any residual glass. As shown below, the limited nature of these solid doping sources enables several high efficiency features to be realized in one furnace step using this simultaneous diffusion technique.

It should be recognized that at no point are the SOD films applied to the solar cell wafers. By applying the same SOD film to each side of a source wafer, as opposed to applying $P$ and $B$ films to opposite sides of a solar cell wafer, we eliminate the potential for cross doping during the film application process, and in addition reduce the handling requirements for the solar cell wafers. In production this would appear to be a distinct advantage over competing technologies since the sources could be made using high throughput techniques such as dip coating or spraying the dopants onto the sources, while the solar cell wafers are processed in parallel via cassette loading techniques.

\section{RESULTS AND DISCUSSION}

\section{III-A Diffusion Profile Engineering Using DOSS Technique}

To demonstrate the flexibility of the DOSS diffusion technique, a range of diluted phosphorus and boron SOD films were used to fabricate sources, followed by a $60 \mathrm{~min}$ diffusion cycle at $1000{ }^{\circ} \mathrm{C}$ in $\mathrm{N}_{2}$. All of the SOD films used in this work are commercially available, and were provided by Filmtronics Corporation, under the product name Boron-A for the boron films and the P500 series for the phosphorus films. Figure 2 shows the resulting sheet resistance dependence on $\% \mathrm{P}_{2} \mathrm{O}_{5}$ in the phosphorus SOD film, and the \% of concentrated Boron$A$ in the boron SOD film. As shown in figure 2 one can

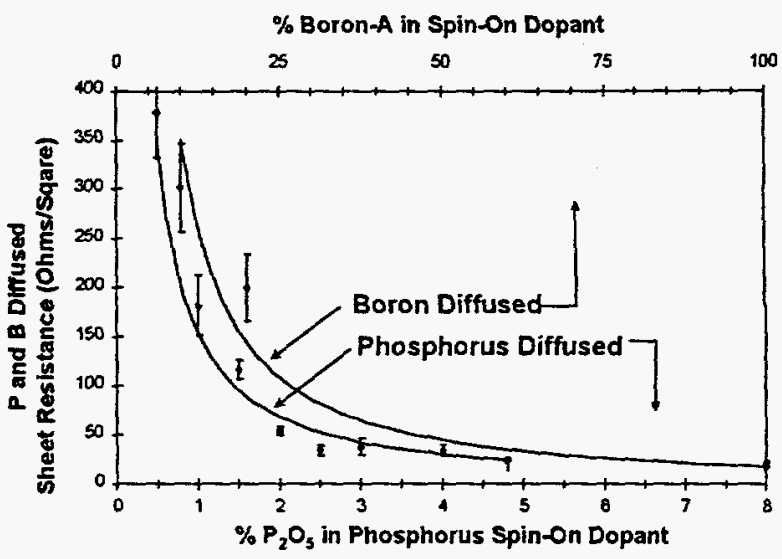

Figure 2. Dependence of sample sheet resistance on source concentration for sources made using $B$ and $P$ SOD films.

simultaneously achieve optimal emitter and BSF profiles, in the range of 20 to $300 \Omega / \square$ by tuning the dopant concentration of the SOD film used to fabricate the source wafers.

The dependence of diffused sheet resistance on source concentration displayed in figure 2 is quite different than what is observed with conventional phosphorus or boron solid sources. Conventional solid sources deposit large quantities of the respective dopant compound $\left(\mathrm{P}_{2} \mathrm{O}_{5}\right.$ or $\left.\mathrm{B}_{2} \mathrm{O}_{3}\right)$ so that the surface concentration is fixed by the solid solubility of the impurity at a given temperature. Thus one is severely restricted in designing a simultaneous diffusion process with conventional solid sources, since the surface concentration of both impurities are pinned at the solid solubility at the diffusion temperature.

The solid sources developed in this work are limited in the concentration of dopant oxides transferred from source to sample, and do not behave as "infinite" solid sources over a wide range of concentrations. This unique feature for solid doping sources allows one to tune the dopant surface concentration to produce optimal emitter and BSF profiles by simply adjusting the dopant concentration of the SOO film used to fabricate the sources. The upper limit for surface concentration is dictated by the solid solubility, at which point the sources behave as conventional solid sources.

\section{III-B. Residual Oxide Thickness}

Figure 3 shows the residual oxide thickness for boron and phosphorus diffused samples resulting from the limited solid doping sources developed in this work. The two sets of data are for boron and phosphorus diffusions at $1000^{\circ} \mathrm{C}$ for 60 min in $\mathrm{N}_{2}$ only, with no in-situ oxide formation. From figure 3 it is clear that the residual glass thickness is very small, and is approximately the same value for both dopants, for sheet resistance $\left(\rho_{s}\right)$ values greater than about $30 \Omega / \square$. For $\rho_{s}$ values below about $30 \Omega / \square$, the glass thickness rises sharply with decreasing $\rho_{\mathrm{s}}$, and the differences in glass thickness between boron and phosphorus diffused samples becomes more pronounced. For most phosphorus emitters of interest, having $p_{s}$ values in the range of 40 
$100 \Omega / \square$, the residual glass thickness ranges from $65-90$ $\AA$. This is about an order of magnitude lower than what is obtained when using conventional solid, liquid, CVD or spin-on doping sources.

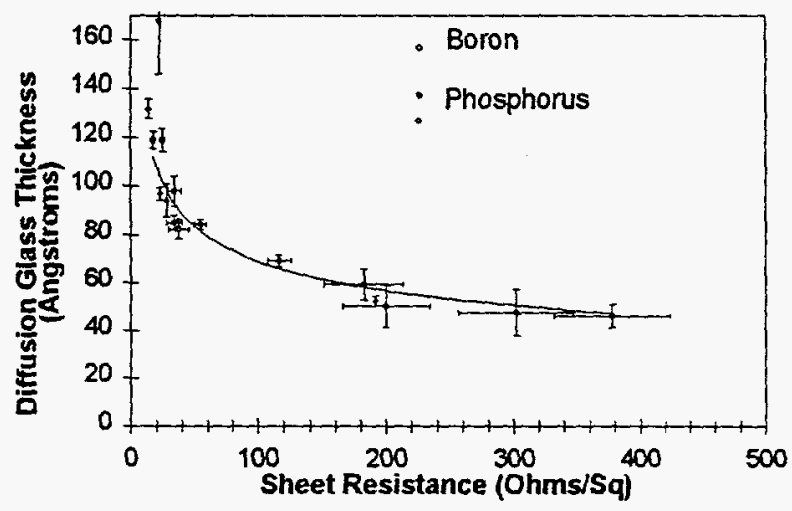

Figure 3. Residual oxide thickness for $P$ and $B$ diffused wafers with no in-situ oxidation.

A physical model is presented below to explain two unique features of the DOSS technique; the tunability of the surface concentration below the solid solubility, figure 2 , and the resulting thin diffusion glass shown in figure 3. These attributes are used to obtain optimal profiles and in-situ surface passivation resulting in low $J_{0}$ values.

\section{III-C. Proposed Model for DOSS Diffusion}

The phosphorus SOD used in this work is an industry-standard solution of $\mathrm{P}_{2} \mathrm{O}_{5}, \mathrm{H}_{2} \mathrm{O}$, tetraethylorthosilane (TEOS), and ethanol. The hotplate bake prior to diffusion serves to drive off the ethanol solvent leaving a glassy film of $\mathrm{P}_{2} \mathrm{O}_{5}, \mathrm{H}_{2} \mathrm{O}$ and TEOS. At diffusion temperatures above about $700^{\circ} \mathrm{C}$, TEOS reacts to form $\mathrm{SiO}_{2}, \mathrm{H}_{2} \mathrm{O}$ and $\mathrm{C}_{2} \mathrm{H}_{4}[6,7]$. It is well known that $\mathrm{P}_{2} \mathrm{O}_{5}$ is extremely hygroscopic [8], and will react with $\mathrm{H}_{2} \mathrm{O}$ intentionally added to the $\mathrm{SOD}$ film, as well as with humidity in the laboratory environment and trace amounts of moisture in the process gasses, to form the volatile species $\mathrm{H}_{3} \mathrm{PO}_{4}$ (phosphoric acid), which has a boiling point of about $400^{\circ} \mathrm{C}$. It is assumed that this is the phosphorus containing species that is transported from the source to the sample wafer. The reverse reaction takes place on the sample wafer resulting in a film of $\mathrm{P}_{2} \mathrm{O}_{5}$ on the sample surface with $\mathrm{H}_{2} \mathrm{O}$ as a byproduct; a process which was found to occur during the direct vaporization of $\mathrm{H}_{3} \mathrm{PO}_{4}$ at elevated temperatures [9]:

$$
\mathrm{P}_{2} \mathrm{O}_{5}+3 \mathrm{H}_{2} \mathrm{O} \underset{\text { Sample }}{\underset{\text { Source }}{\rightleftharpoons}} 2 \mathrm{H}_{3} \mathrm{PO}_{4}
$$

The oxide of phosphorus, $\mathrm{P}_{2} \mathrm{O}_{5}$, deposited on the sample surface proceeds to react with silicon to form $\mathrm{SiO}_{2}$ and $P$, which preferentially diffuses into silicon:

$$
2 \mathrm{P}_{2} \mathrm{O}_{5}+5 \mathrm{Si} \rightarrow 5 \mathrm{SiO}_{2}+4 \mathrm{P}
$$

For the case of limited doping sources, we propose that the starting thickness of $\mathrm{P}_{2} \mathrm{O}_{5}$ formed on the sample surface is extremely thin, and is limited by the dose of $\mathrm{H}_{3} \mathrm{PO}_{4}$. During the diffusion cycle reaction (2) is essentially driven to completion, resulting in a thin layer of $\mathrm{SiO}_{2}$ rich glass on the sample surface, and the surface concentration of $\mathrm{P}$ below the solid solubility. Thus by controlling the concentration of $\mathrm{P}_{2} \mathrm{O}_{5}$ in the SOD film, we can limit the dose of $\mathrm{H}_{3} \mathrm{PO}_{4}$, and thus the thickness of $\mathrm{P}_{2} \mathrm{O}_{5}$ on the sample, allowing the underlying silicon to consume virtually all of the available phosphorus for concentrations below the solid solubility. This result is notably different than conventional $\mathrm{SiP}_{2} \mathrm{O}_{7}$-based solid sources which are designed to be reused for hundreds of hours. These conventional solid sources continually deposit a stream of $\mathrm{P}_{2} \mathrm{O}_{5}$ on the sample wafers, which results in a thick layer of diffusion glass on the surface [10], and thus provides a supply of phosphorus which exceeds the solid solubility. In this case the surface concentration is dictated by the solid solubility of $\mathrm{P}$ in $\mathrm{Si}$, and thus the only degrees of control is the diffusion temperature and time. But by fabricating solid doping sources in the limited source regime we now have a third degree of control in addition to temperature and time; the source concentration.

The situation for boron sources fabricated from a boron SOD film is analogous to phosphorus: The BoronA film used in these experiments is a proprietary boronbased polymer dissolved in cyclohexane and diluted with toluene, which converts directly to $\mathrm{B}_{2} \mathrm{O}_{3}$ at about $450^{\circ} \mathrm{C}$ [11]. It is likely that $\mathrm{B}_{2} \mathrm{O}_{3}$ is directly transported from the source to sample wafer, although $\mathrm{HBO}_{2}$ which has a much higher vapor pressure than $\mathrm{B}_{2} \mathrm{O}_{3}$ is known to form in the presence of even trace amounts of moisture [12]. For the case of limited boron diffusions, the reactions on the sample surface proceed as in the case of phosphorus:

$$
2 \mathrm{~B}_{2} \mathrm{O}_{3}+3 \mathrm{Si} \rightarrow 3 \mathrm{SiO}_{2}+4 \mathrm{~B}
$$

resulting in a thin $\mathrm{SiO}_{2}$-rich glass layer and a boron concentration below the solid solubility.

To test the above hypothesis; that the emitter surface concentration depends on the starting thickness of $\mathrm{P}_{2} \mathrm{O}_{5}$ on the sample wafers, diffusions were carried out using planer and textured sample wafers which face opposite sides of the same phosphorus source. By etching [111] oriented pyramids in the [100] sample surface, the surface area is increased by a factor of $1 / \cos \phi=1.73$ over a planer surface. Thus for a limited dose of $\mathrm{H}_{3} \mathrm{PO}_{4}$, the resulting thickness of $\mathrm{P}_{2} \mathrm{O}_{5}$ on the textured sample will be less than the planer sample since the available quantity of $\mathrm{P}_{2} \mathrm{O}_{5}$ is spread out over a larger surface area. According to the proposed model this should result in a lower surface concentration on the textured wafers or equivalently a higher sheet resistance. As shown in figure 4 this is indeed the case.

Figure 4 shows that for low concentrations of $\mathrm{P}_{2} \mathrm{O}_{5}$ in the SOD films used to fabricate the sources, the textured wafers have a higher sheet resistance than the planer wafers by a factor of about 2 when facing the same sources. As the $\% \mathrm{P}_{2} \mathrm{O}_{5}$ in the SOD film is increased, the difference in $\rho_{s}$ is reduced until the $\rho_{s}$ 's for the textured and planer wafers approach the same value for the "infiniten $\mathrm{P}_{2} \mathrm{O}_{5}$ case, which corresponds to that of conventional solid sources. 
For comparison, diffusions were carried out using $\mathrm{POCl}_{3}$ and conventional $\mathrm{SiP}_{2} \mathrm{O}_{7}$ - based solid sources, with textured and planer wafers diffused

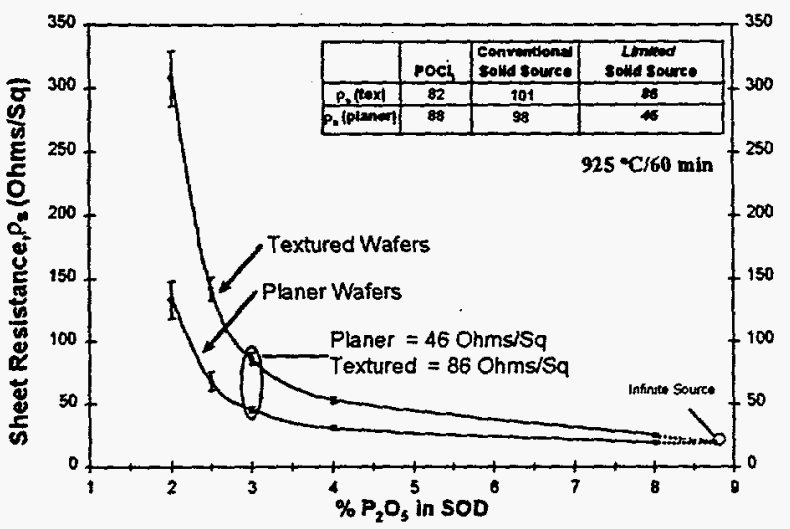

Figure 4. Dependence of sample sheet resistance on source concentration for textured and planer wafers.

simultaneously. As shown in the inset table of figure 4, the values of $\rho_{\mathbf{s}}$ for textured and planer wafers is nearly identical when using $\mathrm{POCl}_{3}$ and conventional solid sources. However, in the case of limited solid sources used in the DOSS technique, the same source can produce an $86 \Omega / \square$ textured emitter and a $46 \Omega / \square$ planer emitter. This feature can be used to obtain an in-situ selective emitter for screen-printed contacts: By selectively texturing the field region of an emitter using a SiN texture mask, one can simultaneously diffuse a flat grid region of $46 \Omega / \square$, and a textured field region of 86 $\Omega / \square$, taking full advantage of the in-situ oxide passivation found in the Doss technique

\section{III-D. In-Situ Oxide Surface Passivation}

Table 1 shows the results of emitter saturation current density $\left(J_{0}\right)$ measurements at $25^{\circ} \mathrm{C}[13]$, made on heavy and light boron and phosphorus diffusions, with insitu oxide passivation. As shown in table 1, a heavy $(25$ $\Omega / \square)$ boron BSF typically used in high efficiency cell designs results in a Jo value of $417 \mathrm{fA} \mathrm{cm}^{2}$. By forming a lighter boron diffusion of $110 \Omega / \square$, coupled with in-situ oxide passivation this $J_{0}$ value can be reduced to 92 $f A / \mathrm{cm}^{2}$. This value for $J_{0}$ is a factor of two higher than reported by King [ref] for $126 \Omega / \square$ boron diffusions formed using CVD doped oxides, but is still capable of producing low values of effective recombination velocity at the highlow $\left(p p^{+}\right.$) junction. For a $2 \Omega$-cm (p-type) material, the effective surface recombination velocity at the $\mathrm{pp}^{+}$ junction can be expressed as:

$$
S_{p p^{+}}=\frac{N_{A}}{q n_{i}^{2}}\left(1+\frac{\Delta n}{N_{A}}\right) J_{o}
$$

which corresponds to an $S_{p p}+=56 \mathrm{~cm} / \mathrm{s}$ under low level injection $\left(\Delta n<<N_{A}\right)$. In practice the true value of $S_{p p}+$ will be higher due to additional recombination at the ohmic contacts to the (full) $p^{+}$BSF. But, by reducing the metal coverage by forming point contacts or screen-printing an Al/Ag grid, the effects of contact recombination can be reduced.

\begin{tabular}{|c|c|c|}
\hline Dopant & Sheet Resistance & $\mathrm{J}_{0}$ \\
\hline Boron & $25 \Omega / \square$ & $417 \mathrm{fA} / \mathrm{cm}^{2}$ \\
Boron & $110 \Omega / \square$ & $92 \mathrm{fA} \mathrm{cm}^{2}$ \\
Phos. (with Ox.) & $90 \Omega / \square$ & $67 \mathrm{fA} \mathrm{cm}^{2}$ \\
Phos. (w/o Ox.) & $90 \Omega / \square$ & $809 \mathrm{fA} / \mathrm{cm}^{2}$ \\
Phos. (with Ox.) & $43 \Omega / \square$ & $130 \mathrm{fA} / \mathrm{cm}^{2}$ \\
\hline
\end{tabular}

Table 1. Jo measurements for heavy and light boron and phosphorus diffusions.

The benefits of in-situ oxide passivation of phosphorus diffused emitters formed using SOD-coated source wafers are shown in Table 1. As shown in Table 1 , for a $90 \Omega / \square n^{+}$diffusion with in-situ oxide passivation, the resulting $J_{0}$ value is low, resulting in $J_{0}=67 \mathrm{fA} / \mathrm{cm}^{2}$. By removing the in-situ oxide, the $J_{0}$ value increases to 809 $\mathrm{fA} / \mathrm{cm}^{2}$, demonstrating the superb passivating qualities of the in-situ oxide provided by the DOSS technique. By forming a heavier $\mathrm{n}^{+}$diffusion $(-43 \Omega / \square)$ which is appropriate for screen printed contacts, we have found that the Jo value shows only a moderate increase to 130 $f \mathrm{~A} / \mathrm{cm}^{2}$, which is still capable of producing high open circuit voltages. That we can obtain a low Jo of 130 $\mathrm{fA} / \mathrm{cm}^{2}$ for a (semi-opaque) $43 \Omega / \square$ phosphorus diffusion is most likely due to the fact that the diffusions are carried out well below the solid solubility. This reduces the probability of introducing significant surface damage, commonly referred to as a "dead layer" [14], allowing the device to take advantage of the high-quality in-situ oxide passivation.

Work is currently under way to introduce screenprinted contacts to the cell fabrication process using the $43 \Omega / \square$ phosphorus emitter and $110 \Omega / \square$ boron BSF shown in Table 1. Measurements of the specific contact resistance $\left(\rho_{c}\right)$ by the transmission line method have resulted in average $\rho_{\mathrm{c}}$ values of $2.9 \mathrm{~m} \Omega-\mathrm{cm}^{2}$ for $46 \Omega / \square$ phosphorus diffusions and $4.3 \mathrm{~m} \Omega-\mathrm{cm}^{2}$ for $85 \Omega / \square$ boron diffusions using $\mathrm{Ag} / \mathrm{P}$ and $\mathrm{Ag} / \mathrm{Al}$ pastes respectively. Computer modeling indicates that greater than $18 \% \mathrm{Cz}$ screen-printed cells should be feasible if effective surface passivation can be maintained and the metal area coverage kept to a minimum $(\leq 10 \%)$.

\section{III-C. Impurity filtering and Gettering Using DOSS Technique}

Historically it has been difficult to obtain high minority carrier lifetimes when using a boron SOD film as a dopant source, when spun directly onto a wafer. The impurity levels of contaminants such as $\mathrm{Fe}, \mathrm{Cr}, \mathrm{Cu}$ and $\mathrm{Ni}$ are typically present in the $10 \mathrm{ppb}$ range for the SOD films used in this work [11], which can lead to significant bulk lifetime degradation. In the present work it was discovered that by fabricating separate boron sources using a relatively impure boron SOD film, one could filter out much of the contaminants present in the film, liberating a relatively "pure" flux of $\mathrm{B}_{2} \mathrm{O}_{3}$ from the filmcoated source wafer. 
The effectiveness of this impurity filtering action is seen in figure 5 , in which the boron-diffused bulk lifetime, $\tau_{b}$ is shown as a function of injection level, $n$. Two sets of source/sample wafers were used in these experiments, in which a $100 \%$ Boron-A film was applied to a p-type $2.3 \Omega-\mathrm{cm}$ float zone silicon wafer which was then used as a source for an adjacent $2.3 \Omega-\mathrm{cm}$ sample wafer. Special care was taken in these experiments to insure cleanliness of the spin-on process. The first set of wafers, labeled Sample 1 and Source 1 respectively in figure 5 were diffused at $1000^{\circ} \mathrm{C}$ for $60 \mathrm{~min}$ in $\mathrm{N}_{2}$, with no in-situ oxide grown. The second set of source/sample wafers were subjected to an additional $66 \mathrm{~min}$ in-situ oxidation at $1000^{\circ} \mathrm{C}$ to grow a thick thermal oxide and are labeled Sample 2 and Source 2. As shown in figure 5 , the difference in bulk lifetime between the source and sample wafers is large for the cases with and without the thick in-situ oxide. In both cases the impurity filtering action resulted in high bulk lifetimes in excess of $1 \mathrm{~ms}$ for the sample wafers, but degraded the source wafers to a lifetime of $227 \mu$ s and $5.9 \mu$ s for the non-oxidized (case 1) and oxidized cases (case 2 ) respectively. We have observed this behavior numerous times using 5 different lots of boron SOD film manufactured over the past 2 years. By indirectly doping the samples via film-coated source wafers, impurities in the boron SOD film are diffused into the sources but are not transported to the samples, resulting in lifetimes in excess of $1 \mathrm{~ms}$ for these high-quality Fz-Si wafers. Thus the sources act to filter out impurities from the boron SOD film, allowing a relatively pure layer of $\mathrm{B}_{2} \mathrm{O}_{3}$ to deposit on the sample surface.

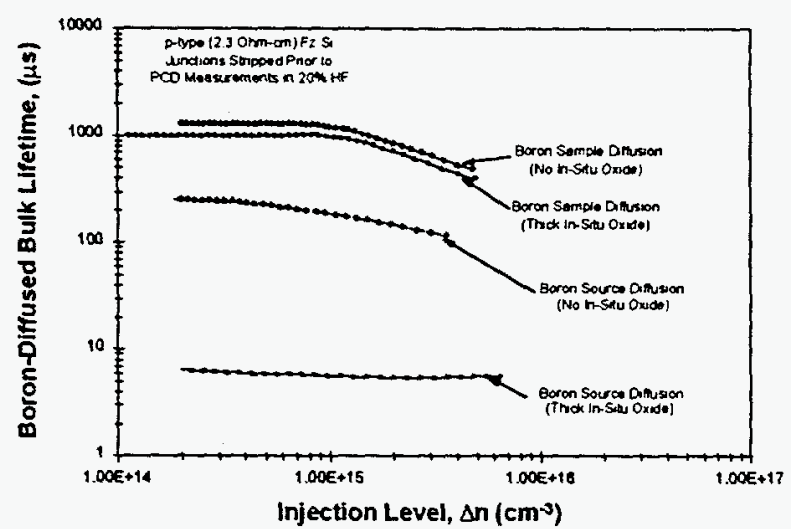

Figure 5. Impact of impurity filtering action on bulk minority carrier lifetime for oxidized and un-oxidized boron diffusions.

It is interesting to note that the lifetime of the oxidized Source 2 wafer $(5.9 \mu \mathrm{s})$ was significantly lower than the non-oxidized Source 1 wafer $(227 \mu \mathrm{s})$ in figure 5 . We attribute this to a reduction in the gettering effectiveness of the boron BSF as a result of dopant redistribution during the 66 minute in-situ oxidation. During the in-situ oxidation, boron preferentially segregates into the growing oxide layer so that the surface concentration is reduced. Similar results have been reported in the use of boron nitride solid sources [15], in which it was proposed that further oxidation after diffusion in $\mathrm{N}_{2}$ leads to re-injection of impurities from the
$\mathrm{BSF}$ to the bulk region as the surface concentration is reduced. In addition, workers at Bell Laboratories [16] have recently shown that the ability to getter impurities which form metal-acceptor complexes (e.g. Fe, Mn and Cr) from a $p^{-}$to $p^{+}$region strongly depends on the difference in boron concentration between the two regions, expressed as

$$
\frac{\left[X_{i}^{+}\right]_{p^{+}}}{\left[X_{i}^{+}\right]_{p^{-+}}}=e^{\frac{\Delta E_{f}}{k T}}
$$

where $X_{i}^{+}$is the ionized interstitial metal concentrations and $\Delta E_{f}$ is the fermi-level offset between the $p^{-}$and $p^{+}$ regions.

While we have not attempted to identify the lifetime limiting impurities in this work, our results are consistent with those reported in the literature for boron gettering of the metallic impurities present in the Boron-A SOD film. These results suggest that clean boron diffusions resulting from the impurity filtering mechanism in the DOSS technique, coupled with effective boron gettering can be used to significantly enhance the minority carrier lifetime of solar grade materials. The simplicity and flexibility of the DOSS diffusion technique makes this an ideal approach to study boron and phosphorus (co)gettering phenomena while maintaing the ability to produce high efficiency solar cells in one furnace step.

\section{III-D. High Efficiency Solar Cell Fabrication}

The ability of the DOSS technique to produce optimal emitter and BSF profiles, in-situ oxide surface passivation and maintain high bulk lifetimes is demonstrated by high efficiency solar cell fabrication. The cell structure used is referred to as a Simultaneously diffused, Iextured, in-situ oxide AR-coated solar cell (STAR cell). Figure 6 shows the light IV, IQE and reflectance measurements confirmed by Sandia National Laboratories of two STAR cells made on (boron) source and sample wafers, in order to illustrate the power of impurity filtering in this technology. The $4 \mathrm{~cm}^{2}$ random textured cells were fabricated on $2.3 \Omega-\mathrm{cm}$ float zone silicon, in a $60 \mathrm{~min}$ simultaneous diffusion process at $1000{ }^{\circ} \mathrm{C}$ in $\mathrm{N}_{2}$ followed by a $66 \mathrm{~min}$ in-situ oxidation to grow a $-1070 \AA \mathrm{SiO}_{2}$ single layer antireflection coating. Photolithography was used for the front and back contacts, with point contacts made to a full boron BSF in order to use the (back) in-situ oxide as a dielectric for a back side reflector. This type of structure has recently produced (confirmed) efficiencies as high as $20.1 \%$ in one furnace step [17] using the DOSS diffusion technique.

Figure 6 illustrates the merit of using separate boron source wafers, which resulted in an efficiency of $19.4 \%$ for the cell adjacent in the diffusion furnace to the $15.2 \%$ cell to which the boron SOD film was applied. Both cells were fabricated out of the same float zone silicon material and had the same emitter and BSF sheet resistances. The $4.2 \%$ boost in absolute efficiency by using a separate boron source is attributed to the filtering of impurities present in the boron SOD film, a process 
which according to figure 5 results in bulk minority carrier lifetimes in the vicinity of $1 \mathrm{~ms}$ for this material.

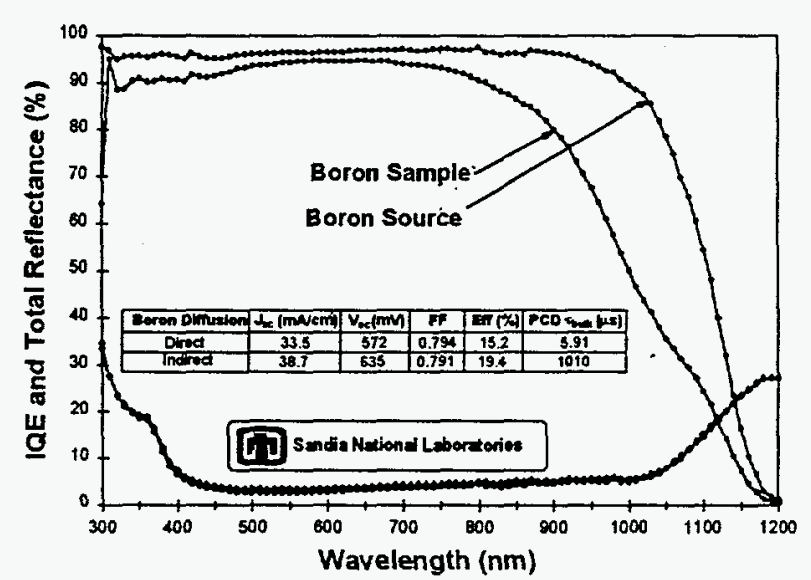

Figure 6. Impact of impurity filtering action on solar cell efficiency, showing a $4.2 \%$ increase in (absolute) efficiency for the sample device as compared to the corresponding source device.

In order to reduce the processing temperature from $1000^{\circ} \mathrm{C}$ and improve the surface passivation and AR coating properties, a second generation (STAR-II) process is currently under development. In the STAR-II design, the diffusion temperature is reduced to $925^{\circ} \mathrm{C}$ and the oxidation time reduced to $10 \mathrm{~min}$. These process changes produce a lighter boron BSF $(-100 \Omega / \square)$ and a thinner oxide so that a $\mathrm{ZnS} / \mathrm{MgF}_{2}$ DLAR-coating can be used with the textured emitter. PECVD $\mathrm{SiO}_{2}$ is deposited on the back in-situ oxide as a dielectric for a back side reflector, and point contacts made to the (full) transparent boron BSF. Initial STAR-II results are encouraging, giving efficiencies of $20.3 \%$ on $4 \mathrm{~cm}^{2} \mathrm{Fz}(2.3 \Omega-\mathrm{cm})$ cells and $19.1 \%$ on $200 \mu \mathrm{m}$ thick $\mathrm{Cz}(10 \Omega-\mathrm{cm})$ cells. Internal quantum efficiency measurements are shown in figure 7 for the $19.1 \% \mathrm{Cz}$ STAR-II cell. The high long wavelength quantum efficiency demonstrates that in addition to good surface passivation and bulk lifetime, effective light trapping is achieved in this $200 \mu \mathrm{m}$ thick device, due to the $\mathrm{Si} / \mathrm{SiO}_{2} / \mathrm{Al}$ back side reflector. In comparing STAR-1 and STAR-II Fz cells, a $10 \mathrm{mV}$ increase in $V_{\alpha c}$ is obtained which can be largely attributed to the transparent, oxide passivated boron BSF. Further improvements are expected through optimization of the surface passivation and AR coating properties, in order to reach the goal of producing $20 \% \mathrm{Cz}$ cells in one furnace step using the STAR-II process. Research is also underway to integrate screen printing with the STAR technology to produce manufacturable, high efficiency solar cells.

\section{CONCLUSION}

In conclusion, we have made significant advances in the DOSS simultaneous boron and phosphorus diffusion technique. It is shown that the boron and phosphorus source wafers can be fabricated from SOD films, which provide a high degree of flexibility in process design and eliminate the need for separate $\mathrm{POCl}_{3}$ and $\mathrm{BBr}_{3}$ diffusion furnaces. Several efficiency- enhancing features of the DOSS technique, such as insitu oxide surface passivation, impurity filtering and boron gettering are presented and quantified. These efficiency enhancement techniques are combined to produce 19$20 \%$ efficient $\mathrm{Fz}$ and $\mathrm{Cz}$ solar cells in a single thermal cycle, using sources and equipment which are completely compatible with the current PV technology base of conventional diffusion furnaces.

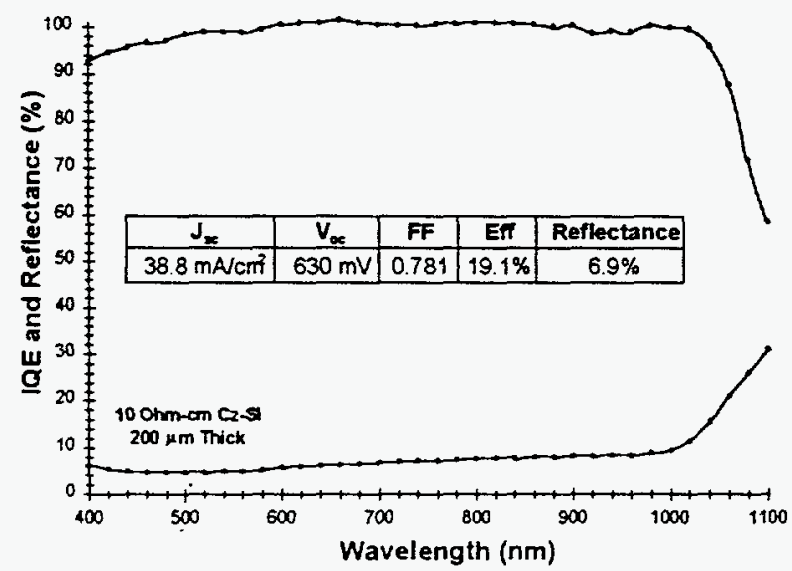

Figure 7. IQE of $19.1 \%$ STAR-II cell on $200 \mu \mathrm{m}$ thick Cz-Si.

\section{REFERENCES}

[1] P. Basore, J. Gee, E. Buck, K. Schubert, D. Ruby, Solar En. Mat. and Solar Cells, V34 pg 91 (1994).

[2] B. Hartiti, S. Sivoththaman, R. Schindler, J. Nijs, J.C. Muller, P. Siffert, IEEE $1^{\text {st }}$ World Conf. On PV Energy (1994)

[3] A. U. Ebong, C. B. Honsberg, Solar En. Mat. and Solar Cells, V 44, pg 271 (1996).

[4] T. Krygowski, A. Rohatgi, J. Electrochem. Soc., Vol 144, pg 346 (1997).

[5] T. Krygowski, P. Sana, G. Crotty, A. Rohatgi, Proc. $25^{\text {th }}$ IEEE Photovoltaic Spec. Conf. (1996).

[6] K. Fujino, Y. Nishimoto, N. Tokumasu, K. Maeda, J. Electrochem. Soc., Vol 137, pg 2883 (1990).

[7] B. Gelernt, Semiconductor International, March 1990, pg 82.

[8] N. Nagasima et. al., J. Electrochem. Soc., Vol 121, pg 434 (1974).

[9] T. Koval, US Patent 4360393 (1982).

[10] J. R. Flemish, R. E. Tressler, J. Ruzyllo, J. Electrochem. Soc., Vol 138, pg 233 (1991).

[11] Tim Selzer, Filmtronics (Private Communication).

[12] A. Yeckel, S. Middleman, AlChE Spring National Meeting, pg35 (1987).

[13] D. E. Kane, R. M. Swanson, Proc. 18 $18^{\text {th }}$ IEEE Photovoltaics Spec. Conf., pg 578 (1985).

[14] S. R. Wenham, M. A. Green, Prog. In Photovolt., Vol4 pg 3 (1996).

[15] T. Saitoh, T. Warabisako, Tech. Digest for $9^{\text {th }}$ Workshop on Crystalline Silicon Solar Cells pg 29 (1996).

[16] J. L. Benton, et. al. J. Appl. Phys., Vol 80, pg 3275 (1996).

[17] T. Krygowski, A. Rohatgi, IEEE Transac. Elec. Dev., Jan 89 To be published.

ACKNOWLEDGMENTS This work was supported by Sandia National Laboratories under contract AO-6162.

Sandia is a multiprogram laboratory operated by Sandia Corporation, a Lockheed Martin Company, for the United States Department of Energy under contract DE-ACO4-94AL85000. 